\title{
BENCHMARKING OF RISK MANAGEMENT METHODS WITH REGARD TO VARIATIONS AS A SOURCE OF RISK
}

\author{
S. Rapp ${ }^{\otimes}$, M. Altner and A. Albers \\ Karlsruhe Institute of Technology, Germany \\ $\bigotimes$ simon.rapp@kit.edu
}

\begin{abstract}
When developing new systems, there is always some kind of reference to existing systems. Various approaches aim at describing qualitatively different characteristics of such connections, often depicted as some form of variation. Among other things, this is done with regard to innovation potential and development risk. In this paper, we investigate the extent to which established methods of risk management refer to modelling approaches for variations by means as mentionend above. After a litertaure search 11 methods and method clusters are analyzed more in detail within a method benchmark.
\end{abstract}

Keywords: risk management, engineering change, design guidelines, product generation engineering (PGE), reference system

\section{Introduction}

When developing new systems, there is always some kind of reference to existing systems. Various approaches aim at describing qualitatively different characteristics of such connections. Among other things, this is done with regard to innovation potential and development risk. Henderson and Clark, (1990), for example, associate four types of innovation with different variations, shown in Figure 1. This considers that the different types of innovation require different skills and result in different challenges.

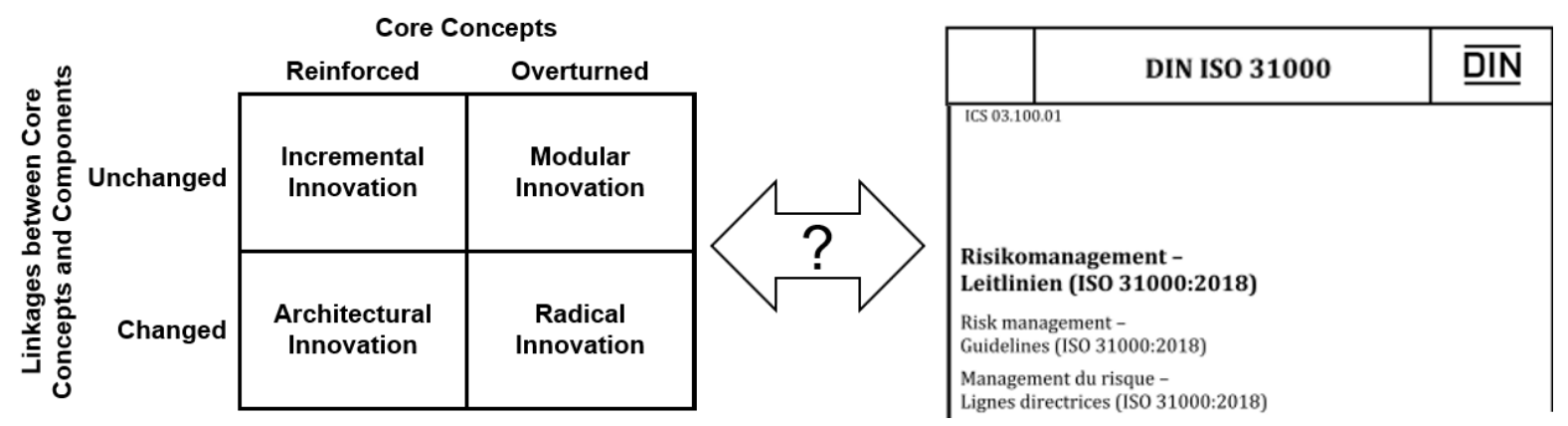

Figure 1. Types of change connected to innovation and the relation to risk management

We want to investigate the extent to which risk management methods and guidelines, such as for example the ISO 31000 (2018) consider qualitative differences in the relation between new developed systems and underlying existing systems. Furthermore, we analyse how the methods differ with regard to their application in the development process. 


\section{State of the art}

According to Feldhusen and Grote (2012), the sum of all steps to achieve a partial result, from the product idea to the finished product, is referred to as the "product development process" (PDP). Products that are based on technical innovations and succeed on the market can be considered an innovation according to Schumpeter (1934).

Market success is favoured by the focus on customers and fulfilling their needs. The definition of customers includes among other things individuals, companies and states. The Kano model supports the developer in this. (Kramer and Kramer, 1997; Kano et al., 1984; Feldhusen and Grote, 2012). It shows how various features - enthusiasm, performance and basic features - influence customer satisfaction. Over time, enthusiasm will become performance features and these will become basic features. For this reason, companies must continue to ensure that new products or subsequent generations of products are given new features of enthusiasm and/or performance. Development processes thus create new opportunities for companies to succeed in the market. Activities in the development of new product generations, which build up on already existing systems are described by various approaches in different ways.

\subsection{Building up on existing systems}

According to Wright (1997), technical changes are one of the driving forces in the development of products. The following section explains approaches to variation or change in product development.

Jarratt et al. (2011) define engineering change as a change made to components, drawings or software. The changes are made during the development process or the product life cycle as well as after they have been released. Technical changes can often be distinguished into critical and non-critical changes (Langer et al., 2012). Critical changes are defined as changes that can endanger the entire project because they have a high impact on resources used and other components in the form of change propagation. However, critical changes also offer great opportunities. Standard changes, on the other hand, are minimal changes, such as changes to the geometry or corrections to errors in the documentation.

In various publications, the propagation of changes in the development of products and the severity and probability of the effects on the product are examined more closely. (Terwiesch and Loch, 1999; Jarratt et al., 2011; Eckert et al., 2004).

A relevant factor are the causes of variations and their description. According to Eckert, the causes of changes are divided into "Emergent Changes" that come from the product and "Initiated Changes" that come from the environment.

The model of PGE - Product Generation Engineering according to Albers et al. (2015) describes the development of technical systems by the three types of variation: carryover variation (CV), embodiment variation (EV) and principle variation (PV). Developed systems are always based on reference systems or reference system elements which define the basic structure of the developed products. Reference systems may include but are not limited to products from the own company, the competition, other fields or theoretical concepts.

Technical changes can occur in the entire development process and during the product life cycle.

\subsection{Risk \& Risk management in product development}

The "International Organization for Standardization" defines risk as the "effect of uncertainty on objectives" (ISO 31000 2018). In this paper, the effects of risks and the types of risks are examined in more detail. Both aspects in this work are based on Oehmen and Lindemann (2016) where the financial, time-related, qualitative and other dimensions of the effects are considered.

The categories are divided into four categories. The approach of Oehmen and Lindemann serves as a basis, which classifies the risks according to their influence in near, middle and far. Together with the considerations of Park (2010), Keizer et al., (2005) and Denning, (2013) results in the subdivision of risks into four areas: the product, management and processes, supply chain and external factors.

ISO31000 (2018) serves as a framework for risk management. It helps to make risks controllable in different processes and consists of the following areas: Definition of the context, risk identification, risk analysis, risk assessment, risk handling, communication \& consultation, monitoring \& verification. 
Risk management activities are implemented using various methods. There are several studies and collections of risk management methods that are currently in use. (Oehmen et al., 2010)

(Chauhan et al., 2018). Among the regularly occurring methods are the FMEA, the QFD, checklist, scenario method, benchmarking, analogy process and sensitivity analyses.

The FMEA (DIN EN 60812, 2015) identifies and evaluates potential errors through a structured approach in order to avoid the occurrence of errors. The QFD (Feldhusen and Grote, 2012; Reich and Paz, 2008) ensures the quality of a product by converting customer requirements into specific services and functions and by comparing them with reference products. Checklists are used to gather experiences from past projects and present them for future use. The sensitivity analysis examines how variations and changes of influences affect the product. The Analogy Process (Madauss, 2017; Savci and Kayis, 2006) searches for similar projects in the past and analyses the similarities to identify risks. The benchmarking method compares a product to the competition and analyses all products according to specific features or properties (Feldhusen and Grote, 2012). Scenario Methods create plausible projections of the future and analyse how the object of interest behaves in this context (Fink and Siebe, 2016).

In most cases, these methods are categorized according to risk management frameworks. In addition to the methods already presented, there are other methods that consider variations or changes. These include the DRBFM (Shimizu et al., 2010) in which risks are identified by comparing the current development with the preceding product and examining the variations. The PGE risk portfolio (Albers et al., 2017), (Albers et al., 2018) in which risks of new developments and their elements are assessed with regard to types of variation by means of the PGE model, origin of reference systems and hierarchy level. The DSM Change-Propagation-Matrix (Eckert et al., 2004) in which risks are identified on the basis of propagation and criticality. In addition, the VMEA examines how key properties are influenced by changing parameters. (Pavasson and Karlberg, 2011).

\section{Research questions}

One motivation for the description models from Section 2.1 and the qualitative differentiations made there, in the relationship between existing and new systems, is the assessment of project and development risks on the basis of observations from development practice. The methods described in Section 2.2 serve to support risk management in the development of new technical systems. In this paper, we would like to examine the extent to which established methods of risk management refer to the described modelling approaches for product development and the phenomena recorded there. Therefore, the following research questions are the starting point of our investigation:

- How are development risks associated with the relationship between existing systems and newly developed systems based on them?

- To what extent are these relationships with development risks considered in risk management methods?

- To what extent do methods that take these relationships with development risks at least partially into account differ in terms of their application area?

In answering these questions, the term "variation" is essential. It is used in different ways by different approaches. Some explicitly define different types of variation, e.g. the PGE model. Others refer to "changes" or are based more implicitly on some form of variation. In general, variation can be described as an alteration compared to something existing. In this contribution usually applying to systems, but also to their environment. For the investigation in this contribution we apply this general understanding, e.g. for a scale with the values "variation considered / not considered" as well as definitions from individual models, e.g. the classification from the PGE model with carryover- / embodiment- / principlevariation. The latter situations are made clear by descriptions where necessary.

\section{Research methodology}

The approach is divided in three stages (Blessing and Chakrabarti, 2009) and depicted in Figure 2 below. The aim of this paper is to combine the existing pieces of information which exist but are currently not connected with each other and thereby create knowledge that can be used by people developing products. 


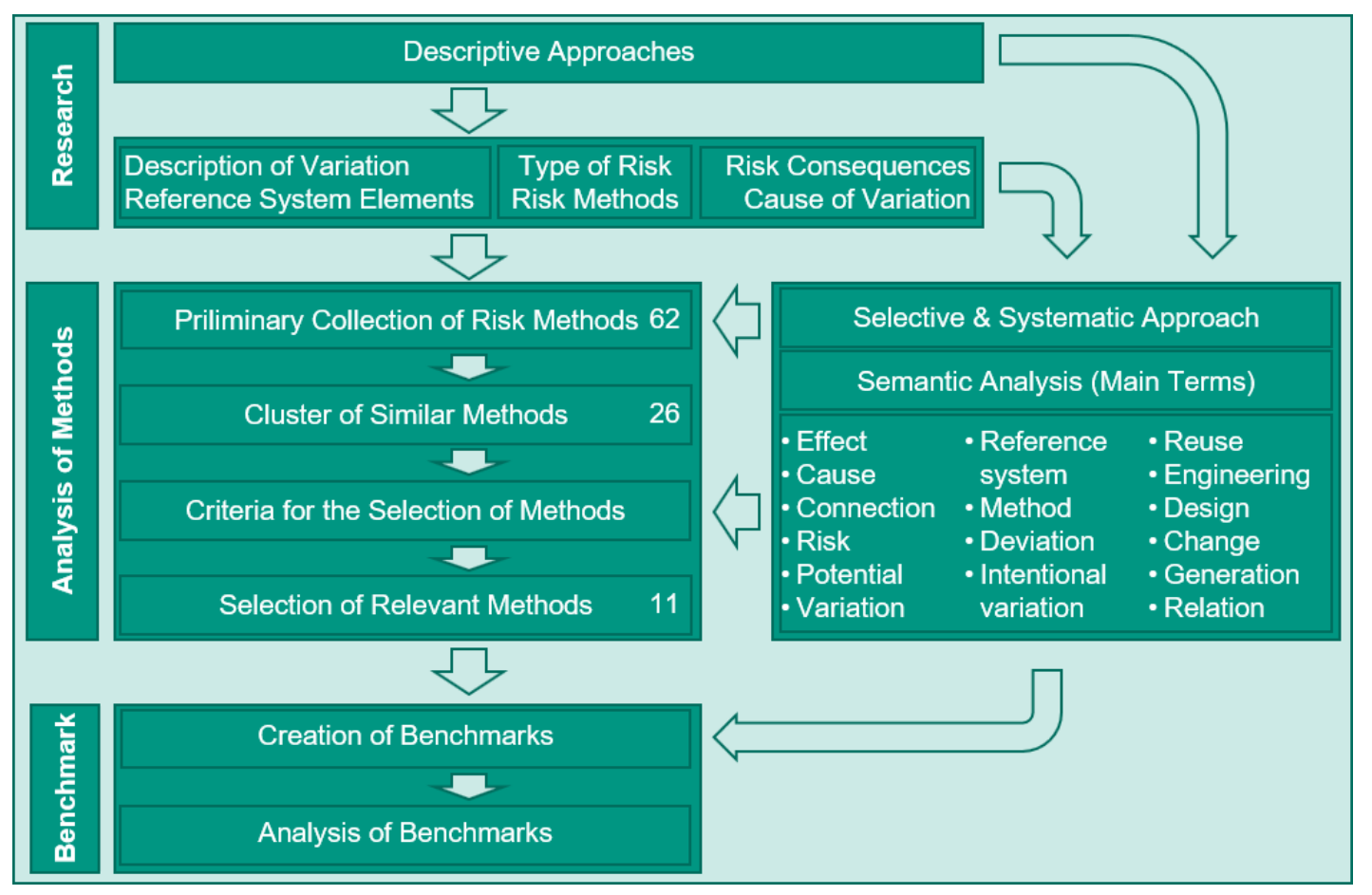

Figure 2. Methodological approach

The first part dealt with the research of the descriptive approaches for the definition and analysis of the field of investigation. This was followed by the collection and research of risk causes, effects, species and exactly like the research on changes and variations regarding their cause, description and effect. The research was carried out according to the approach "Qualitative systematic investigation / qualitative evidence synthesis" described by Grant and Booth (2009). A semantic word field analysis served as a starting point for the systematic research. The core terms used for the search were "product development" and "risk", which were supplemented with sub terms from the following main terms "effect", "cause", "connection", "risk", "potential", "variation" and "reference system". The search was also performed with the equivalent terms in German.

The results from the first part form the backbone of the second part of the investigation. The investigation into the methods of risk management consists of the clustering of the methods in groups and the selection of one representative method per cluster. The representative methods are shown in Table 1. It furthermore includes the selection and collection of criteria and the application of these criteria to select methods for the benchmarks. The criteria stem from research that was done in section 2 considering the role of variation in risk management as well as the description of variation. The research of the methods was also based on the procedure described by Grant and Booth. In addition to the terms already mentioned above, the semantic word field analysis included: "method", "deviation", "intentional variation", "reuse", "engineering design", "connection". The relevant dimensions and dimension pairs that are necessary to generate the benchmarks, were selected based on section 2 . The methods were evaluated regarding the dimensions and summarised in these benchmarks.

The analysis of the benchmarks was carried out in the last phase. The aim of the analysis was to find out to which extent the methods used in Phase 1 reflect the relationships identified between risks, variation and technical changes.

\section{Results}

\subsection{Criteria for selection of methods and selected methods}

The selection of methods was based on the two following criteria:

- Methods of risk management

- Consideration of variations or consideration of reference systems 
The focus of this investigation is the consideration of risk in product development. All methods that are analysed must therefore be risk management methods. Hence, the first criteria.

The second criterion is the inclusion of either variation or reference systems which is based on section two. Variations or the existence of reference systems are a crucial aspect when it comes to the use knowledge from existing products. This combined with the previously mentioned relationship between risk and variation in product development forms the second criterion.

Methods that have a similar scope or approach are not considered individually but grouped together in clusters. This is done to avoid the redundant information since the results are transferable to similar methods. the following methods contained in Table 1 were selected for consideration in the benchmarks:

Table 1. Selected methods

\begin{tabular}{|c|c|c|}
\hline $\begin{array}{l}\text { DSM - Change Propagation } \\
\text { (Eckert et al., 2004) }\end{array}$ & $\begin{array}{l}\text { PGE - Risk Portfolio (Albers et al., } \\
\text { 2017; Albers et al., 2018) }\end{array}$ & $\begin{array}{l}\text { FMEA - Failure Mode and Effect } \\
\text { Analysis (DIN EN 60812, 2015) }\end{array}$ \\
\hline $\begin{array}{l}\text { VMEA - Variation Mode and } \\
\text { Effect Analysis (Pavasson and } \\
\text { Karlberg, 2011) }\end{array}$ & $\begin{array}{c}\text { QFD - Quality Function } \\
\text { Deployment (Feldhusen and Grote, } \\
\text { 2012; Reich and Paz, 2008) }\end{array}$ & $\begin{array}{r}\text { Analogy Process (Madauss, 2017; } \\
\text { Savci and Kayis, 2006) }\end{array}$ \\
\hline $\begin{array}{l}\text { Benchmarking } \\
\text { (Feldhusen and Grote, 2012) }\end{array}$ & $\begin{array}{c}\text { Checklists } \\
\text { (Chapman and Ward, 2003) }\end{array}$ & $\begin{array}{r}\text { Sensitivity Analysis } \\
\text { (Heesen, 2009) }\end{array}$ \\
\hline $\begin{array}{l}\text { Scenario Methods } \\
\text { (Fink and Siebe, 2016) }\end{array}$ & \multicolumn{2}{|c|}{$\begin{array}{r}\text { DRBFM - Design Review Based on Failure Mode } \\
\text { (Shimizu et al., 2010) }\end{array}$} \\
\hline
\end{tabular}

\subsection{Selected dimension}

Table 2 shows the dimensions in the left column and the characteristics in the columns on the right and the middle. The dimensions type of variation, variation description and reference system elements are derived from section 2.1. These are dimension that help to describe the aspect of change in the development of products. These are properties that serve to describe changes.

Table 2. Selected dimensions for the benchmark

\begin{tabular}{|l|c|r|}
\hline Dimension & \multicolumn{2}{|c|}{ characteristic features } \\
\hline Type of Variation & Variation not considered & Variation of the Environment \\
\hline & Unwanted variation & Targeted Variation \\
\hline $\begin{array}{l}\text { Reference System Elements } \\
\text { (RSE) }\end{array}$ & No RSE & Internal RSE \\
\hline & External RSE & Internal and External RSE \\
\hline Variation Description & No Variation Description & Carryover Variation \\
\hline & Embodiment Variation & Principle Variation \\
\hline Risk Category & Product & Management \& Processes \\
\hline & Supply-Chain & External \\
\hline
\end{tabular}

"Type of variation" describes how the variation occurs in the product. It differentiates between changes that come from the outside or environment, changes that are caused deliberately and those that are unwanted. This provides the context on how variations are considered in general.

The dimension "reference system elements" is subdivided into systems within and outside the direct reach of the company or development team as well as the combination or neglection of both. This dimension shows which point of reference is used when examining the change. The dimension "variation description" provides a deeper insight concerning the change itself by giving a better description of its character. This description is taken from the descriptive model PGE. The changes that are mentioned by each method description are classified by using the terms: principle, embodiment and carryover variation. The dimension risk category is derived directly from section 2.2 where the characteristic features are already mentioned. The risk categories illustrate the focus of each method and indicate what method might be suited when investigation a specific area of risks. 


\subsection{Method benchmarks}

The following Figures 3-5, show the benchmarks that are used for the assessment of the selected methods. The coloured shapes indicate which characteristic features of the dimensions are considered or used by the methods. Neither the specific shape nor the position of the shapes in a cell or the colour have a special relevance. They just help to distinguish the methods.

Figure 3 shows which categories of risks are considered in combination with the types of variation. It is noteworthy that targeted variations always refer to risks associated with products and do not consider the other risk categories. This might be explained by the focus which is already on the product which is the thing that is changed and therefore the thing most prone to risks. There is also an accumulation in the cell between external risks and variation of the environment. This seems logical since both characteristic features consider the surrounding. Most methods mainly consider the risk category "product", some consider the risks "external" or "supply chain" while only two methods deal with risks that are related to management and processes. This is probably due to the selection of methods and the search strings which were aimed at identifying methods with the focus on product development. Methods with the focus on management have probably not occurred in the search.

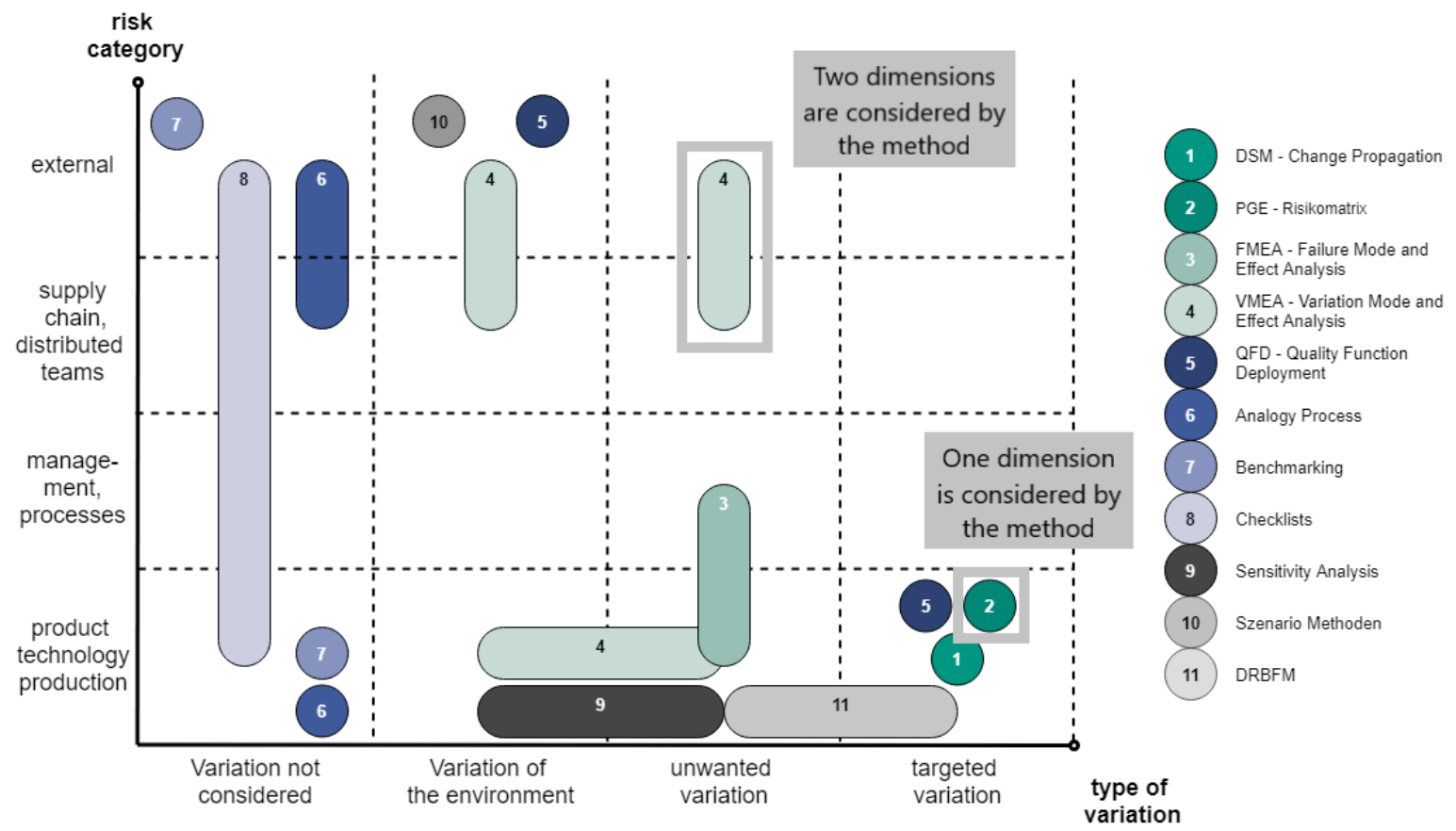

Figure 3. Benchmark of risk management methods considering: "classification of variation" and "risk category"

In Figure 4, the consideration of reference system elements is paired with the types of variation. The field on the bottom left is empty and grey because of the second method selection criterion.

Methods that do not use RSE consider variation from the environment or unwanted variations. That is the reason why the focus goes away from the product. Methods that do not consider variation use knowledge about other products. However, these methods do not go into depth when analysing the cause of the risks. This stands in contrast to methods using RSE or targeted variations.

When company internal RSE are used the methods usually consider the structure of a system, which is usually based on a previous product. It should be noted that changes and their effects are actively investigated when variations are targeted. In combination with external knowledge sources, this increases the knowledge base. The QFD is an exemption. It uses the products of the competition as a reference with the aim to differentiate their own products from them. The PGE risk portfolio on the other hand includes all types of RSE. This includes among other things systems from the competition, from other disciplines and research. 


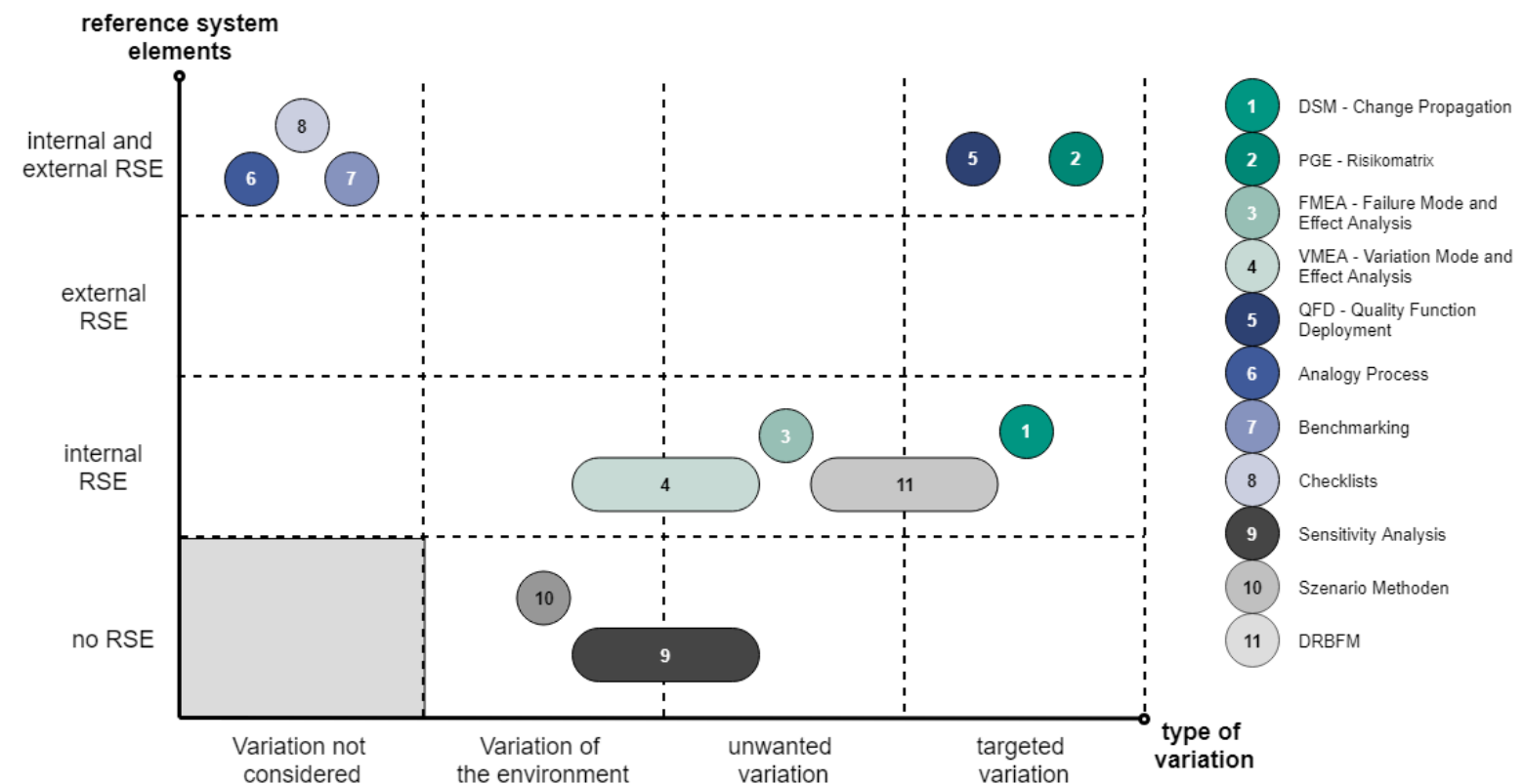

Figure 4. Benchmark of risk management methods considering: "type of variation" and "reference system elements"

In Figure 5 below, the types of variation are compared with the descriptions of variation. Methods without consideration of variation types have quite comprehensively no description of variation. There are no methods that consider both variation of the environment and principle variations.

An explanation might be that the way in which the environment changes is known and only the magnitude changes but not the principles behind them. There are also always methods that consider certain types of variation but do not describe them. The methods PGE risk portfolio and DRBFM are used for targeted variations and use the full spectrum of the variation descriptions. The methods that deal with targeted variations but do not use descriptions of variations are the QFD and DSM - change propagation. The QFD only considers the degree and variation of requirements thus the variation is not explained. The DSM concentrates solely on the effects caused by the variations without describing them.

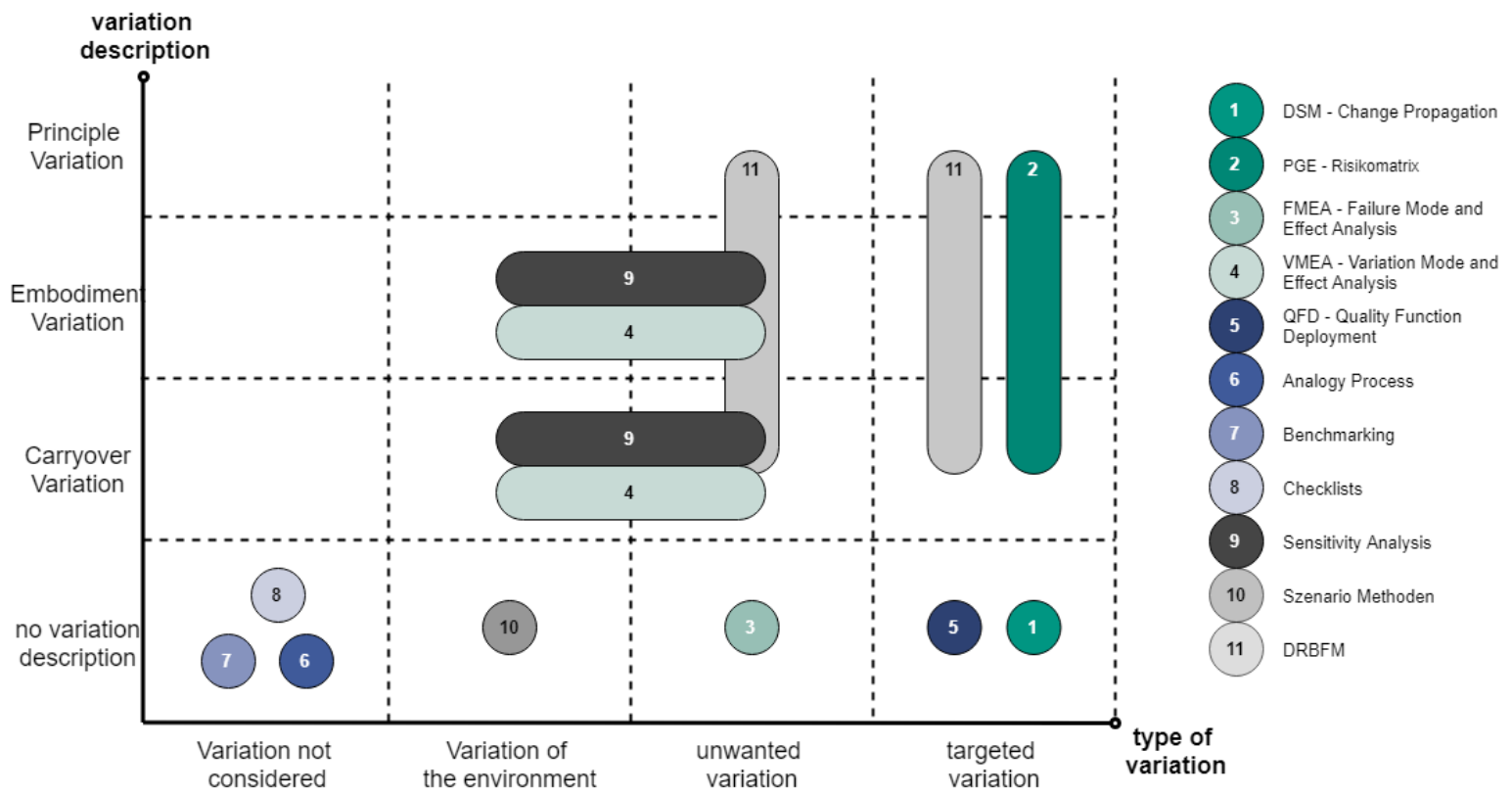

Figure 5. Benchmark of risk management methods considering: "type of variation" and "variation description" 


\section{Discussion}

The papers discussed in section 2.1 and 2.2 already show that there is a connection between development risks and the relation between existing systems and newly developed systems based on them. The relationship between risk and variation was used in section 5.2 when identifying the criteria for the benchmarks. They all aid in the description the development of products and are directly or indirectly linked to risks.

This is additionally supported by the answer to the second research question. The short form of the answer is that the analysed methods show, that the connection between risks and variation are considered and actively used by the risk management methods to identify and cope with risks. Furthermore, the methods work and are well established. That suggests that a relationship exists and is used in practice even if it is not yet fully described and explained. However, the extent to which the relationships are used is limited. The study shows that some methods exist that use variations as well as the origin of the reference system elements to manage the risks. Still none of the methods that were analysed in section five consider all characteristic features of variation description, type of variation, reference system elements or categories of risks. The extent to which relationships between existing systems and newly developed systems that are based on them and risks are considered by the methods is explained in the following paragraphs by discussing the benchmark results.

The examination of the methods regarding the reference systems and the types of variation in Figure 4 shows that there are some methods that only consider either RSE or types of variation. No methods were found in the study that cover all RSE and simultaneously deal with unwanted variations or changes from the environment. There is an accumulation of methods that use internal RSE and cover different types of variation. However, none of these methods considers external RSE. That means that it is either not necessary to consider all elements or that there is potential for additional development. It is furthermore possible that the regularities behind these connections are only implicit knowledge and were therefore not completely utilised.

Figure 5 shows methods and their consideration of variation types and variation descriptions. The methods that regard targeted variation either use an explicit or implicit description of variation. The PGE risk portfolio uses them explicitly and the DRBFM implicitly. Sensitivity analysis and VMEA consider environmental influences or unwanted influences during processes. They are known influences with or without size differences, which act by the same principle. If there is no variation, there is naturally no need for a description, hence those fields remain empty. Methods that that already cover a lot of the characteristic features of variation and risks are particularly interesting for further examination. The fact that they already use some connections makes them more accessible for additional aspects. The interesting methods include the DRBFM, PGE risk matrix and DSM change propagation, as shown in the figures. Although VMEA and sensitivity analyses take variations into account, they are not so interesting because they only focus on deviations outside the product and not on variations of the product itself. FMEA is interesting because it is a widely used method that already has a large coverage. The QFD is also widely used, where the consideration of reference system elements is used to identify costumer requirements. However, this is a variation or adaptation of the requirements of the product. The method is therefore only of limited interest. The remaining methods are not in the focus of interest because they only consider variations or reference systems in a very limited manner.

The application area of the methods can be described in terms of the types of risk that are considered by the methods. This connection is described in Figure 3 where the dimensions are the risk type and the variation type. Methods that deal with specific variations consider only the risks associated with products. Unwanted variations are associated with all risk types by various methods. Overall, most areas of risks are considered by one method or another. The checklist for example covers all areas but is in its approach limited to errors that occurred before. That fact that most methods do connect risks with the occurrence of variations shows that there is a useful connection between those fields.

The research process provides a sound basis by using information directly from the referenced works. The classification of methods required interpretation in cases where the sources did not specifically provide the information or terms used for the work at hand. To limit the potentially subjective influence of individual perspectives, the interpretations where discussed with fellow researchers. 


\section{Outlook}

The study shows that some methods exist that use variations as well as the origin of the reference system elements to obtain an assessment of the risk. However, none of these methods consider all elements of variations or risks. There is therefore the potential to extend, supplement or introduce new methods. The great number of risk management methods together with highly competitive markets shows that there is a high demand for risk management methods with high efficacy.

The results of the benchmark show potential by considering types of variations. The methods investigated considered only a maximum of two characteristics. Furthermore, methods that could consider more and different kinds of reference systems might obtain additional useful information and therefore be more effective. Methods that are probably best suited to be further developed are those that already consider many of the characteristics investigated since those methods would not have to be changed a lot. Among these methods are the PGE Risk Matrix, the DRBFM and the DSM Change Propagation Matrix. The PGE risk matrix can be extended regarding the evaluation of methods and types of risks, as well as the consideration of external and unexpected changes. Currently only targeted variations are used and those are rated as high or low risk. The assessment can be improved with respect to the criticality and the fields that are affected by the change. Although the DRBFM uses changes to the reference system to identify possible errors, it does not fully describe the nature of the changes. Merely the fact that a change is occurring is used to research the effect it has. The description of the change or consideration of other reference systems could assist the developers in classifying the scope of the change and help to eliminating or prevent failures. The DSM-Change Propagation Matrix could provide a more detailed description of the variation. Currently only the structure of the product is considered when looking at the propagation. The different kinds of variation could help to further describe how the risk is propagated in the product and how it interacts with other parts or subsystems. The identification and assessment of failure modes could be improved by investigating the link between variation of changes and potential risks in detail. Of course, other methods can be improved as well by considering the characteristics presented in this paper.

In addition to considering the methods, an expanded study of the relationships between risks, variation, and reference systems can help make the methods more effective which could lead to an improved management of risks. The study provides a basis for the selection and evaluation of risk management methods.

\section{References}

Albers, A., Bursac, N. and Wintergerst, E. (2015), "Produktgenerationsentwicklung - Bedeutung und Heraus forderungen aus einer entwicklungsmethodischen Perspektive", Stuttgarter Symposium für Produk tentwicklung (SSP) Stuttgart, 19. Juni 2015 ; Hrsg.: H. Binz, Vol. 3.

Albers, A. et al. (2017), "Die Frühe Phase der PGE - Produktgenerationsentwicklung", Stuttgarter Symposium für Produktentwicklung 2017 (SSP) Produktentwicklung im disruptiven Umfeld, Vol. 4. https://doi.org/10. 18419/opus-9559

Albers, A. et al. (2018), "Reference Products in PGE - Product Generation Engineering: Analyzing Challenges Based on the System Hierarchy", 28th CIRP Design Conference, Vol. 28, pp. 469-474. https://doi.org/10. 5445/IR/1000084050

Blessing, L.T.M. and Chakrabarti, A. (2009), DRM, a Design Research Methodology, Springer London, London. https://doi.org/10.1007/978-1-84882-587-1

Chapman, C. and Ward, S. (2003), Project risk management: Processes, techniques and insights, 2nd ed., Wiley, Chichester.

Chauhan, A.S. et al. (2018), "Examining the State of Risk Management Research in New Product Development Process", Engineering Management Journal, Vol. 30 No. 2, pp. 85-97. https://doi.org/10.1080/10429247. 2018.1446120

Denning, S. (2013), "What went wrong at Boeing", Strategy \& Leadership, Vol. 41 No. 3, pp. 36-41. https://doi.org/10.1108/10878571311323208

DIN EN 60812 (2015), Fehlzustandsart- und -auswirkungsanalyse (FMEA), Vol. 03.120.01 No. 60812, Beuth Verlag GmbH, Berlin. https://doi.org/10.31030/2328411

Eckert, C., Clarkson, P.J. and Zanker, W. (2004), "Change and customisation in complex engineering domains", Research in Engineering Design, Vol. 15 No. 1, pp. 1-21. https://doi.org/10.1007/s00163-003-0031-7 
Feldhusen, J. and Grote, K.-H. (2012), Pahl/Beitz Konstruktionslehre: Methoden und Anwendung erfolgreicher Produktentwicklung, 8., vollst. überarb. Aufl. 2013, Springer Berlin, Berlin, https://doi.org/10.1007/978-3642-29569-0

Fink, A. and Siebe, A. (2016), Szenario-Management: Von strategischem Vorausdenken zu zukunftsrobusten Entscheidungen, Campus Verlag, Frankfurt, New York.

Grant, M.J. and Booth, A. (2009), "A typology of reviews: an analysis of 14 review types and associated methodologies", Health information and libraries journal, Vol. 26 No. 2, pp. 91-108. https://doi.org/ 10.1111/j.1471-1842.2009.00848.x

Heesen, M. (2009), Innovationsportfoliomanagement: Bewertung von Innovationsprojekten in kleinen und mittelgroßen Unternehmen der Automobilzulieferindustrie, Zugl.: Duisburg-Essen, Univ., Diss, 2009, Gabler, Wiesbaden. https://doi.org/10.1007/978-3-8349-8392-3

Henderson, R.M. and Clark, K.B. (1990), "Architectural innovation: The reconfiguration of existing", Administrative science quarterly, Vol. 35 No. 1, pp. 9-30.

ISO 31000. (2018), Risikomanagement: Leitlinien, Vol. 03.100.01 No. 31000, 12th ed., DELTAdoc, BEST Collection 28; ISO komplett; DVD-2019.

Jarratt, T.A.W. et al. (2011), "Engineering change: an overview and perspective on the literature", Research in Engineering Design, Vol. 22 No. 2, pp. 103-124. https://doi.org/10.1007/s00163-010-0097-y

Keizer, J.A., Vos, J.-P. and Halman, J.I.M. (2005), "Risks in new product development. Devising a reference tool", $R$ and D Management, Vol. 35 No. 3, pp. 297-309. https://doi.org/10.1111/j.1467-9310.2005.00391.x

Kramer, F. and Kramer, M. (1997), Bausteine der Unternehmensführung: Kundenzufriedenheit und Unterneh menserfolg, Innovations- und Technologiemanagement, 2. Auflage, Springer, Berlin, Heidelberg. https://doi.org/10.1007/978-3-642-60533-8

Langer, S. et al. (2012), Änderungsmanagement-Report 2012: Studienergebnisse zu Ursachen und Auswirkungen, aktuellen Praktiken, Herausforderungen und Strategien in Deutschland: Änderungsmanagement-Report 2012: Studienergebnisse zu Ursachen und Auswirkungen, aktuellen Praktiken, Herausforderungen und Strategien in Deutschland.

Madauss, B.-J. (2017), Projektmanagement: Theorie und Praxis Aus Einer Hand, 7th ed., Vieweg, Berlin, Heidelberg.

Kano, N. et al. (1984), “Attractive Quality and Must-Be Quality”, Hinshitsu Quality, Vol. 14, pp. 39-48.

Oehmen, J. et al. (2010), "Risk Management in Product Design. Current State, Conceptual Model and Future Research", Proceedings of the ASME Design Engineering Technical Conference, Vol. 1, https://doi.org/ 10.1115/DETC2010-28539

Oehmen, J. and Lindemann, U. (2016), "Risiko- und Chancenmanagement in der Produktentwicklung", In: Handbuch Produktentwicklung, Carl Hanser Verlag GmbH \& Co. KG, pp. 59-98. https://doi.org/10.3139/ 9783446445819.004.

Park, Y.H. (2010), "A study of risk management and performance measures on new product development", Asian Journal on Quality, Vol. 11 No. 1, pp. 39-48. https://doi.org/10.1108/15982681011051813

Pavasson, J. and Karlberg, M. (2011), Variation Mode and Effect Analysis compared to FTA and FMEA in Product Development.

Reich, Y. and Paz, A. (2008), "Managing product quality, risk, and resources through resource quality function deployment", Journal of Engineering Design, Vol. 19 No. 3, pp. 249-267. https://doi.org/10.1080/ 09544820701327947

Savci, S. and Kayis, B. (2006), "Knowledge elicitation for risk mapping in concurrent engineering projects", International Journal of Production Research, Vol. 44 No. 9, pp. 1739-1755. https://doi.org/10.1080/ 00207540500445321

Schumpeter, J.A. (1934), The theory of economic development: An inquiry into profits, capital, credit, interest, and the business cycle, Transaction publishers, New Brunswick.

Shimizu, H., Otsuka, Y. and Noguchi, H. (2010), "Design review based on failure mode to visualise reliability problems in the development stage of mechanical products", International Journal of Vehicle Design, Vol. 53 No. 3, p. 149. https://doi.org/10.1504/IJVD.2010.033827

Terwiesch, C. and Loch, C.H. (1999), "Managing the Process of Engineering Change Orders: The Case of the Climate Control System in Automobile Development", Journal of Product Innovation Management, Vol. 16 No. 2, pp. 160-172. https://doi.org/10.1111/1540-5885.1620160

Wright, I.C. (1997), "A review of research into engineering change management: implications for product design”, Design Studies, Vol. 18 No. 1, pp. 33-42. https://doi.org/10.1016/S0142-694X(96)00029-4 